\title{
Cell Membrane Damage of Prokaryotes and Analysis of the Cell Death Type in Eukaryotes by Fluorescence Microscopy
}

\author{
Larissa Souza Amaral $^{1^{*}}$ and Erich Potrich ${ }^{2}$ \\ ${ }^{1}$ Program Interunits in Bioengineering EESC/FMRP/IQSC, University of São Paulo - USP. \\ São Carlos - SP, 13566-590, Brazil \\ ${ }^{2}$ Department of Chemical Engineering PPGEQ, Federal University of São Carlos - UFSCar. \\ São Carlos - SP, 13566-590, Brazil \\ *Corresponding author
}

\section{A B S T R A C T}

Keywords

Fluorescence microscopy,

Cell membrane damage,

Cell death type,

Prokaryotes, Eukaryotes

Article Info

Accepted:

10 January 2018

Available Online:

10 February 2018
Fluorescence microscopy allows an extensive variety of analyzes in structural biology. Until the beginning of the seventeenth century living beings were limited to macroscopic organisms only, and there was no knowledge of the microscopic universe. Epi-fluorescence and Confocal microscopy appears in 1995 by Marvin Minsky with the aim of increasing the contrast and constructing three-dimensional images by the use of an aperture, allowing a great definition. The use of this microscopic technique is indicated for studies of thin or thick materials, live or pre-fixed and with or without staining by fluorophore molecules. In this study we present the applicability of fluorescence microscopy to identify damage in the cytoplasmic membrane of prokaryotes and mechanisms of cell death in eukaryotes.

\section{Introduction}

\section{The evolution of microscopy}

The current advance of microscopy began in classical antiquity, by Fiorentino Salvino d'Amato in 1285 presenting a "rebirth" through the manufacture of lenses by polishing the glass, which in turn were used by Zacharias Janssen, 1590, which made the first simple microscope, with a 30x increase. Dutch physicist AntonieVan Leeuwenhoek has improved the simple microscope model by making a new model with a 200 -fold increase in which it was possible to visualize bacteria for the first time. Only in the nineteenth century, the maximum limit was reached using visible light (Abramowitz). In the same century binocular microscopes appeared, and soon afterwards, in the twentieth century, the microscope of phase contrast, by Zernicke and the differential contrast, by Normanski (Paddock).

The improvement was in existence until the limitation, which is the big wavelength of the 
radiation (visible light), which prevented the attainment of a higher resolution, led the scientists of the time to look for another type of irradiation, different from the light visible, leading to a higher resolution of the images. Then the physicist Louis de Broglie discovered that the electron beam had a behavior similar to light rays, but had a wavelength of $10,000 \mathrm{x}$ less, that is, the resolution of the image would be much better, and then the electron microscopy (Bradbury, 1967).

In concomitance with the advancement of microscopy, several scientists have emerged enhancing visualizations through lenses, a progress from methods of preparation of biological material for observation, being developed several techniques, such as obtaining ultra-thin cuts and the fixation of cellular structures (Bradbury, 1967).

Confocal microscopy emerged in 1955 through Marvin Minsky driven by the desire to obtain images of biological events in vivo. In Minsky's original confocal microscope the punctual source of light was produced by a needle hole placed in front of a source of a zirconia arc. The light point was focused by an objective lens for the sample, and the light passing through it was focused by a second objective lens for a second bore, which had the same focus as the first bore, i.e. was confocal with it. Any light that passed through the second hole hit a low noise photomultiplier, which produced a signal that was related to the brightness of the light. The second pre-vented orifice, the light from above or below the plane of focus of the photomultiplier. This is the key to confocal approach, i.e., to eliminate light out of focus or "burn" in the sample of spatial filtering. Minsky also described another version of the microscope used a single objective lens and a dichromatic mirror arrangement. This is the basic configuration of most modern confocal systems used for fluorescence images (Paddock).

\section{Image formation by fluorescence microscopy}

Confocal microscopy is the technique of optical microscopy that contributes to the understanding of biological processes at the cellular level. A number of previously poorly understood cellular processes such as intracellular trafficking of vesicles can now be better understood. This is allowed since the confocal microscopy is also based on the use of vital dyes (which do not require fixatives or permeabilizing agents to cross the plasma membrane), which allow the study of living cells. The confocal microscope uses, as light sources, the argon or helium/neon lasers or, more rarely, mercury and xenon lamps (such as fluorescence microscopes). The confocal scanning microscope uses a laser as the light source. Its optical system is the same as that of traditional fluorescence, differs in illumination that is performed in some points illuminated by the laser (Witkowski et al., 2016; Schlafer and Meyer, 2017).

A laser is reflected by a dichroic mirror (transparent mirror for a certain wavelength and reflective to another) for an objective. The objective focuses the laser in the sample where it is desired to generate fluorescence. Soon after, the signal from this fluorescence is received by the objective, the beam passes through a filter and reaches a detector that has a pinhole placed in front of it (Fontes, 1999). Another fact that can be observed in Figure 1 is that the incident laser forms an excitation cone in the sample. And, in order for the light from the out-of-focus points to be rejected, a pinhole conjugated to the focal plane of the lens is placed.

To construct the images, the microscope uses a mirror responsible for scanning the $\mathrm{x}$-axis 
and another for the $y$-axis, sweeping the focus of the laser across the $x-y$ plane of the sample. For each swept point, the value of the signal intensity emitted by it is detected and stored, and with this "mapping" an intensity map of the swept $x-y$ plane is formed. The image is constructed by assigning the intensity value measured to each pixel on the computer screen. By varying the focus of the objective, images are obtained for each $\mathrm{x}-\mathrm{y}$ plane of the sample. A three-dimensional image is constructed by superimposing each image of these planes (Thoma, 2007). The function of the plane $\mathrm{f}(\mathrm{x}, \mathrm{y})$ can be characterized by luminescence $\mathrm{i}(\mathrm{x}, \mathrm{y})$, which is the amount of light incident on the scene being observed and reflectance $\mathrm{r}(\mathrm{x}, \mathrm{y})$ being the amount of energy reflected or transmitted objects.

Obtaining the values of the image $\mathrm{f}(\mathrm{x}, \mathrm{y})$, is performed by a sensor that can be a photomultiplier, a photodiode or a sensor specific for the type of energy to be detected. After obtaining the image by the sensor, the image is then discretized, this because the sensor obtains an image given by a continuous function that to be used in a computer being possible the digital processing, it must be presented in a discrete, discontinuous way. Thus the coordinates $(\mathrm{x}, \mathrm{y})$ become discrete with representation in the matrix form given by: $\mathrm{MxN}$ where $\mathrm{M}$ and $\mathrm{N}$ are powers of 2 (Stelzer, 2005).

The value $\mathrm{f}(\mathrm{x}, \mathrm{y})$ is quantized by converting the continuous value of the function into a discrete value generally in the range $(0.2 \mathrm{k}-1)$, where $\mathrm{k}$ is a natural number and $2 \mathrm{k}$ is the number of gray levels in the image. For example, if an image has 24 levels of gray, it means that the continuous values of the image will be represented by 16 levels of gray. Therefore, the values used in the image will be represented by integers in a discrete way, allowing the image to be processed in a digital computer (Fellers and Davidson).

\section{Comparison between wide field fluorescence microscopy and confocal fluorescence microscopy}

Traditional fluorescence microscopy is performed on a wide field microscope, also known as Epi-Fluorescence Microscopy. Its characteristics are: high contrast, high sensitivity (50 fluorophores $\left./ \mu \mathrm{m}^{3}\right)$, multiple marking, allows the analysis of fixed or live samples, has high marking specificity and rapid image acquisition. On the other hand Confocal laser scanning fluorescence microscopy allows confocal fluorescence images and has the same characteristics, with the addition of spatial resolution, which increases the time of acquisition of the images. Due to the sensitivity of the photoelectric detectors and the electronic control of the signal intensity, images that are not very evident in fluorescence microscopy are more clearly observed in confocal fluorescence microscopy (Witkowski et al., 2016). In Figure 2 it can be seen a series of images that compare selected view fields in traditional wide field and laser scanning confocal fluorescence microscopy.

In $A$ and $D$, there is a thick section of human cord tissue. A significant degree of structural detail was observed in the images obtained with Confocal Scanning Microscopy. In B and $\mathrm{E}$, there are muscle fibers of rats. In the image obtained by confocal microscopy we can see a striated topography not visible in the b-image (fluorescence microscopy). In $\mathrm{C}$ and $\mathrm{F}$, one has the grain of sunflower pollen. There is a dramatic difference between the images obtained by the two techniques, confocal microscopy reveals color difference and an envelope (Fellers and Davidson).

In order to choose which measure is most interesting for the desired analysis, one must also consider the emission and excitation lengths of the fluorophores to be used. 
Fig.1 Comparison between wide field fluorescence microscopy and confocal fluorescence microscopy (Available in: http://www.olympusconfocal.com/theory/confocalintro.html)

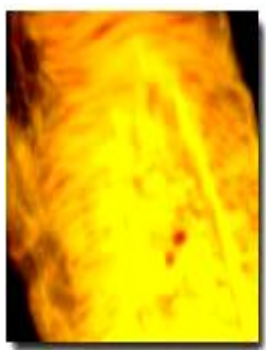

(a)

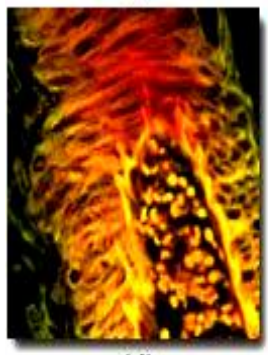

(d)

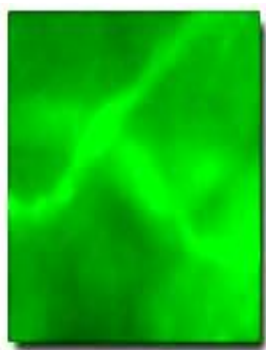

(b)

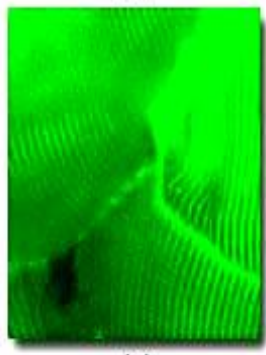

(e)

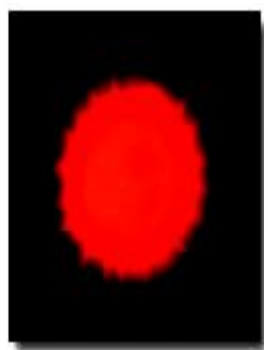

(c)

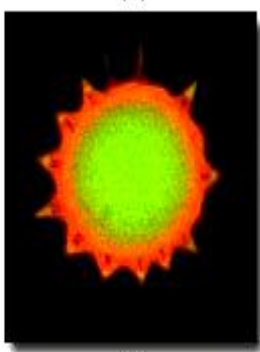

(f)

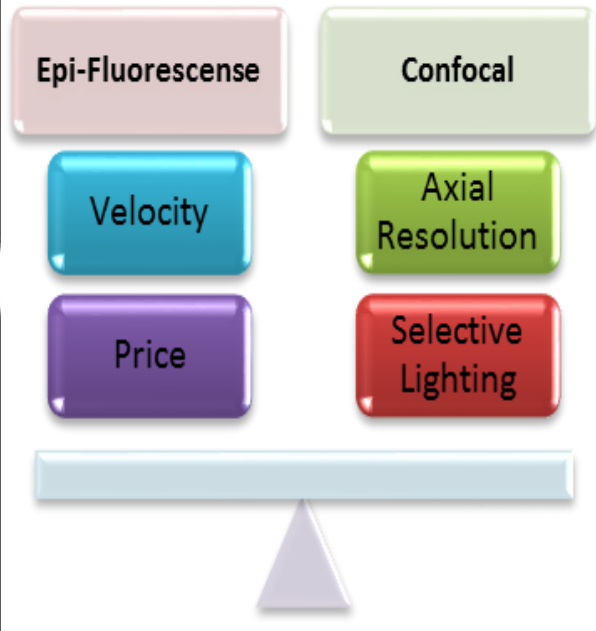

Fig.2 Observation of microorganisms by fluorescence microscopy (Epi-fluorescence and Confocal) using the live/dead kit (A) Acinetobacter baumanni (Loehfelm et al., 2008), (B) Escherichia coli, and (C) Micrococcus luteus (Ali et al., 2018), (D) Mycoplasma putrefaciens (McAuliffe et al., 2006)
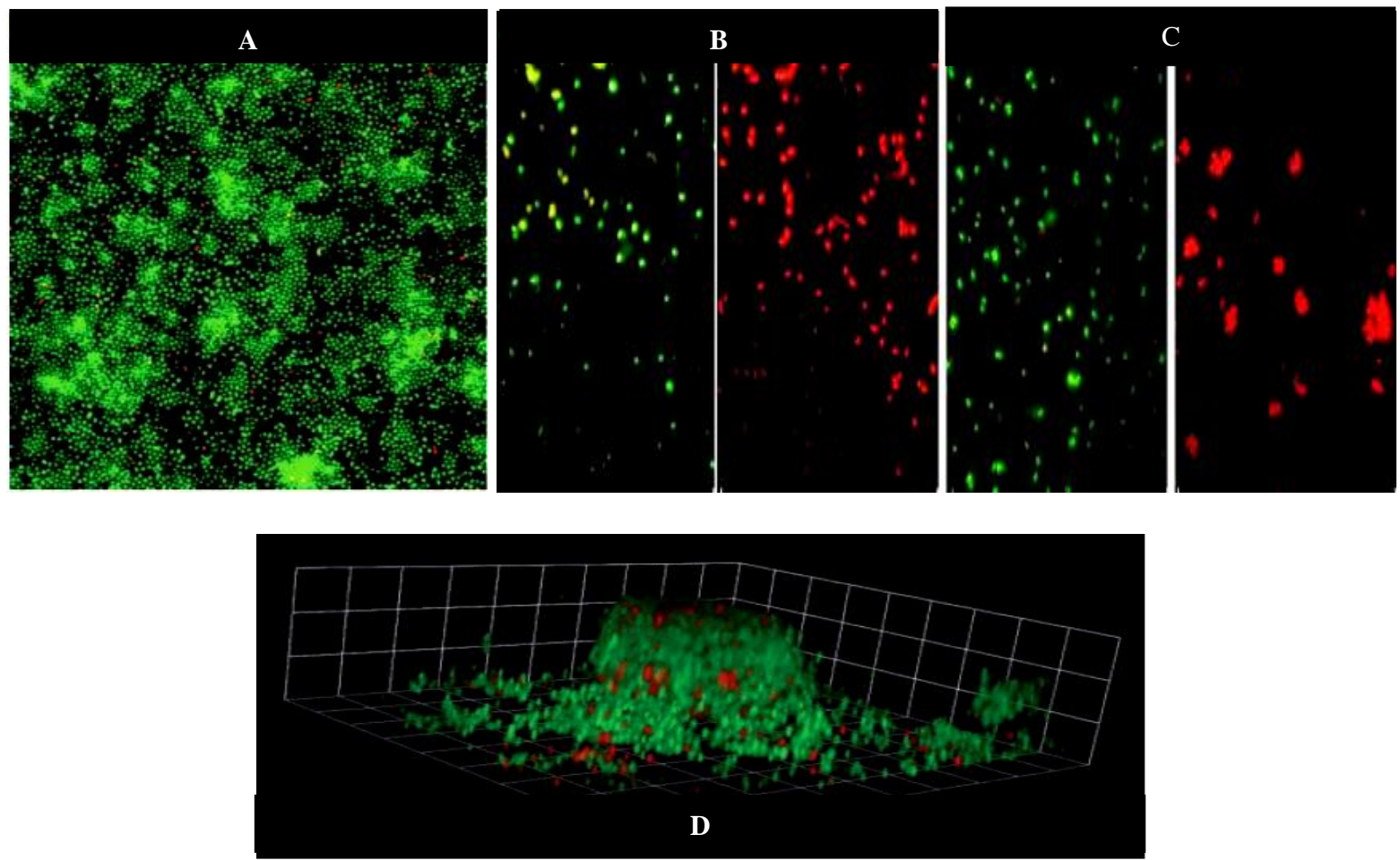
Fig.3 Morphological comparison between Gram-positive (A) and Gram-negative bacteria (B). Red: Cell wall present in both bacterial structures. Blue: Cytoplasmic membrane present in both bacterial structures. Green: Protein porina present in both bacterial structures but in grampositive in the internal membrane and gram-negative in internal and outer membrane. Pink: Exclusive components of gram-positive and, Yellow: Exclusive components of gram-negative

\section{Gram-positive Bacteria (A)}

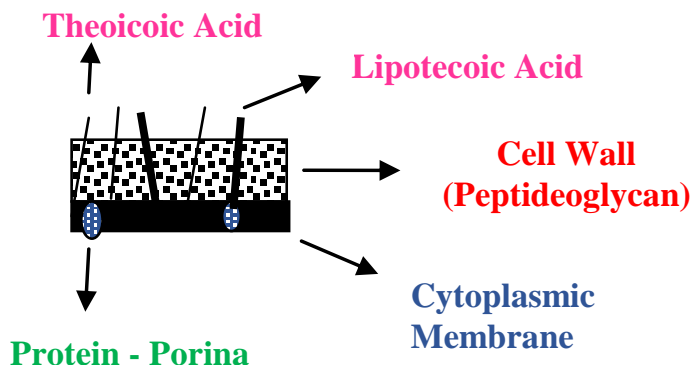

\section{Gram-negative Bacteria (B)}

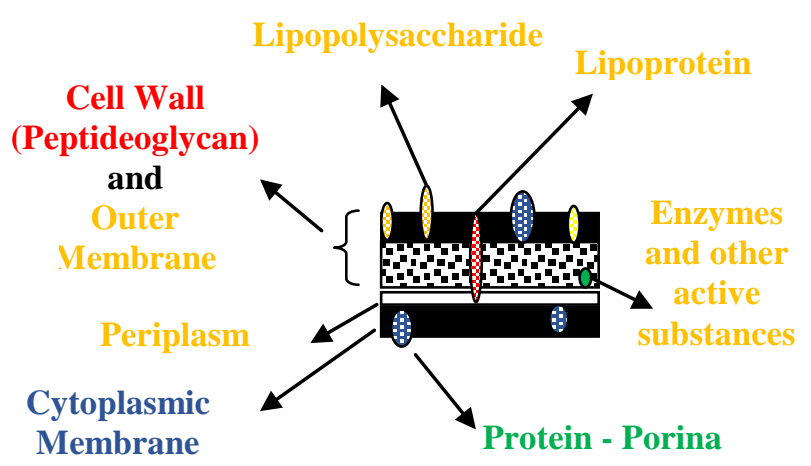

Fig.4 (A-F) Fluorescence images with acridine orange and ethidium bromide staining Apoptotic and necrosis morphology detection. (A) fish Channa striata kidneycell lines and (B) Channa striata gill cell lines (Majeed et al., 2014), (C) HepG-2 cell line, (D) CC-1 cell line and (E) RD cell line (Dilusha et al., 2016) and $\left(\mathrm{F}_{1-4}\right)$ MDA-MB-231 cancer cells

(Mohammadjavad et al., 2014)
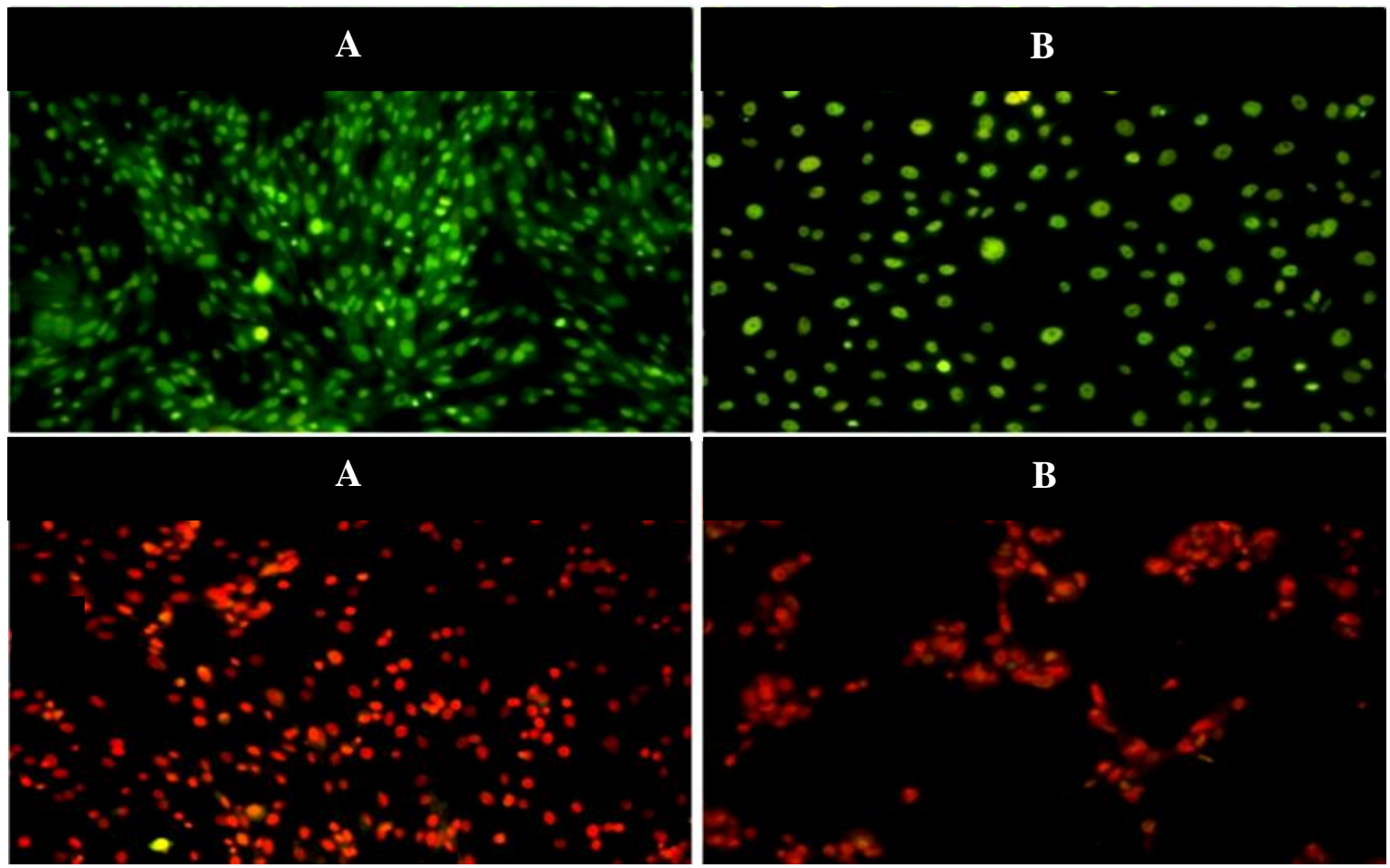

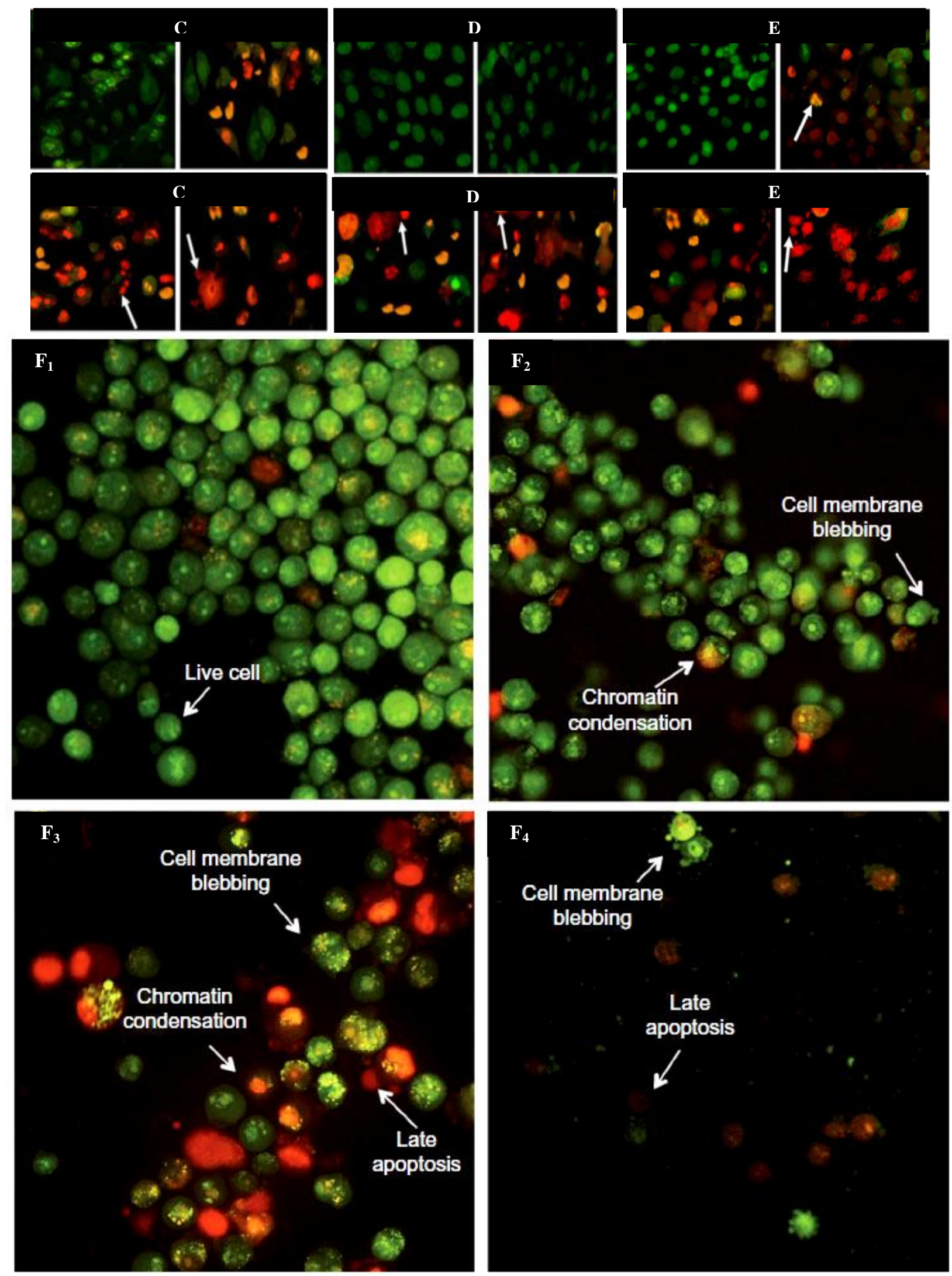
Table.1 Differences between wide field and confocal microscopy

\begin{tabular}{|c|c|c|}
\hline APPLICATION & WIDE FIELD & CONFOCAL \\
\hline Cell count & Ideal & $\begin{array}{c}\text { Excellent for adhered cells, } \\
\text { poor for suspended cells }\end{array}$ \\
\hline $\begin{array}{c}\text { Total Fluorescence } \\
\text { intensity }\end{array}$ & Ideal & $\begin{array}{c}\text { Excellent for flat cells, bad } \\
\text { for bulky cells } \\
\text { Dependent of the tests }\end{array}$ \\
\hline $\begin{array}{c}\text { Microrganisms } \\
\text { Subcellular image }\end{array}$ & $\begin{array}{c}\text { Excellent for flat cells, bad } \\
\text { for bulky cells }\end{array}$ & Excellent \\
\hline $\begin{array}{c}\text { Large structures in high } \\
\text { resolution }\end{array}$ & $\begin{array}{c}\text { Small fields of view } \\
\text { Thick samples }\end{array}$ & $\begin{array}{c}\text { Needs Z-stack, auto focus or } \\
\text { deconvolution }\end{array}$ \\
\hline $\begin{array}{c}\text { Fluorescent compounds } \\
\text { Needs washings }\end{array}$ & $\begin{array}{c}\text { Ideal (rejection of any } \\
\text { fluorescence from another } \\
\text { focus) }\end{array}$ \\
\hline Co-localization & Not indicated & Ideal \\
\hline Z-stack; 3D reconstruction & Not indicated & Ideal \\
\hline Laser applications (FRAP) & N/A & Ideal \\
\hline
\end{tabular}

Table.2 Morphological and biochemistry characteristics of the necrosis and apoptosis (Ozawa, 1995; Elmore, 2007; Trump et al., 1997; Kewei, 2014)

\begin{tabular}{|c|c|c|}
\hline CHARACTERISTICS & NECROSIS & APOPTOSIS \\
\hline \multirow[t]{8}{*}{ Morphological } & Blebbing of membrane integrity & Alterations in membrane asymmetry \\
\hline & Swelling of cytoplasm & $\begin{array}{l}\text { Budding of plasma membrane without } \\
\text { loss of integrity }\end{array}$ \\
\hline & Mitochondrial swelling & $\begin{array}{l}\text { Mitochondrial permeability transition } \\
\text { due to pore formation }\end{array}$ \\
\hline & Calcification & Shrinking of cytoplasm \\
\hline & Disintegration of organelles & $\begin{array}{l}\text { Aggregation of chromatin at the nuclear } \\
\text { membrane }\end{array}$ \\
\hline & Cell lysis & Condensation of nucleus \\
\hline & & Formation of membrane bound vesicles \\
\hline & & Fragmentation of cell into smaller bodies \\
\hline \multirow[t]{5}{*}{ Biochemistry } & $\begin{array}{l}\text { Features have no energy } \\
\text { requirement }\end{array}$ & $\begin{array}{l}\text { Translocation of phosphatidylserine from } \\
\text { the cytoplasmic to the extracellular side } \\
\text { of the membrane }\end{array}$ \\
\hline & $\begin{array}{l}\text { Loss of regulation of ion } \\
\text { homeostasis }\end{array}$ & $\begin{array}{l}\text { Tightly regulated enzymatic process and } \\
\text { activation of caspase cascade }\end{array}$ \\
\hline & Random digestion of DNA & $\begin{array}{l}\text { Release of mitochondrial factors } \\
\text { (cytochrome c,AIF)into cytoplasm }\end{array}$ \\
\hline & \multirow[t]{2}{*}{ Postlytic DNA fragmentation } & $\begin{array}{c}\text { Energy (ATP)-dependent and active } \\
\text { process }\end{array}$ \\
\hline & & $\begin{array}{l}\text { Mono- and oligonucleosomal length } \\
\text { fragmentation of DNA }\end{array}$ \\
\hline
\end{tabular}


Table 1, the imaging target is shown and which would be the most efficient type of microscopy for analysis.

Visualization of membrane damage of prokaryotes by fluorescence microscopy (Epi-fluorescence and confocal)

In microbiology, the observation of membrane damage can be made by the use of fluorophores molecules that mark in different ways. An example of a molecule widely used for years is Acridine Orange (AO), however it has the disadvantage of distinguishing active and dead physiological cells, making it difficult to understand. In contrast, it is hypothesized that the reaction of bacteria with AO allows such discrimination according to the manner in which the $\mathrm{AO}$ reacts with single-stranded nucleic acids, resulting in red to orange fluorescence. On the other hand if AO reacts with double-stranded nucleic acids, there is green fluorescence. This metachromatic feat is influenced by the AO ratio versus nucleic acid (American Public Health Association, 1992; Feters et al., 1991; Gordon et al., 1995).

Currently for the detection of microbial metabolism live/dead kit is used. This kit provides a two dye fluorescence assay based on membrane integrity with extensive use in various microorganisms in the literature as Acinetobacter baumanni (Loehfelm et al., 2008), Mycoplasma putrefaciens (McAuliffe et al., 2006), Escherichia coli, and Micrococcus luteus (Ali et al., 2018). In Figure 3, it is possible to observe the visualization of the microorganisms with the kit which allows to distinguish between live and dead (Loehfelm et al., 2008; McAuliffe et al., 2006; Ali et al., 2018).

There is the mixture of SYTO® 9, a green fluorescent nucleic acid dye and the propidium iodide nucleic acid dye also being fluorescent red. These dyes vary in the ability to penetrate healthy bacteria. SYTO® 9 alone, marks all bacteria, whether with membranes intact or not. On the other hand, propidium iodide penetrates only in bacteria that present membrane damage reducing SYTO® 9 when both are present.

Bacterial membrane damage can occur due to several factors. To know what affects the bacterial membrane is important to know the classification of bacteria (Fig. 4).

Gram-negative and gram-positive bacteria show structural similarities, however they are morphologically different. In gram-positive bacteria, there are tecoic and lipotecoic acids on the surface of the cell wall. In gramnegative bacteria there is the presence of lipopolysaccharides and lipoproteins besides two external and one internal membranes.

The damage of the cytoplasmic membrane occurs directly in gram-negative, due to its outer membrane, subsequently affecting the internal membrane or by rupturing the cell wall of gram-positive allowing osmotic rupture through membrane damage. However gram-negative presents proteins in the outer membrane that function as efflux pumps, absorbing and expelling bactericidal/ bacteriostatic agents out of the bacteria ensuring more resistance to the treatments.

The disintegration of the cytoplasmic membrane occurs using antibiotics, disinfectants, radiations, and (photo) oxidations, among others. Antibiotics act inhibiting the synthesis of the cell wall composed of peptideoglycan. Inhibiting bacterial growth and causing death, as example have beta-lactams, vancomycin (Bartash and Nori, 2017) and bacitracin. Betalactams inhibit cross-linking of the cell wall, vancomycin interferes with the addition of new subunits in the cell wall (murine 
pentapeptide), and finally, bacitracin prevents the addition of cell wall subunits by inhibiting recycling of the membrane lipid carrier. On the other hand disinfectants, radiations and (photo) oxidations by singlet oxygen or free radicals act directly on the membrane causing the osmotic instability and leading the microorganism to death.

The visualization of the bactericidal and bacteriostatic effect becomes satisfactory when using physical tools. Fluorescence microscopy allows this analysis, bringing positive evidence of membrane damage and being of important use for survival analysis.

Visualization of cell death type in eukaryotes by fluorescence microscopy (Epi-fluorescence)

The mechanism of cell death (apoptosis or necrosis) induced by some type of process can be evaluated by fluorescence microscopy. Two markers, ethidium bromide (EB) and acridine orange (AO) are used. Viable cells are marked by AO and appear green and with organized structures. Apoptotic cells are labeled by both fluorophores and appear orange or green with condensed or fragmented chromatin. Necrotic cells appear similar to the alive ones, except for the red color (Smith et al., 2012). In the Figure 4, can be observed the apoptotic and necrotic morphology detection for several cell lines (Majeed et al., 2014; Dilusha et al., 2016; Mohammadjavad et al., 2014).

Necrotic cells exhibit morphological changes such as, swelling of the entire cell and its organelles, followed by rupture of the plasma membrane, release of intracellular components, including proteolytic enzymes, loss of homeostasis, and slow disappearance of the nucleus are exhibited in this type of death. Apoptotic cells also present changes in their morphology. Among them are condensation of chromatin, nuclear fragmentation, formation of apoptotic bodies and cellular shrinkage (Golstein and Kroemer, 2007; Edinger and Thompson, 2004).

When the death of a living organism occurs following the enzymatic degradation of the cellular components by enzymes released by the lysosomes (autolysis), the process is called necrosis. On the other hand, when there is death by active process in which the cell undergoes contraction and condensation of its structures, there is fragmentation and phagocytosis by neighboring cells or macrophages, without autolysis, the process is called apoptosis (Ozawa, 1995). Apoptosis is a programmed cell death, with physiological response to remove old cells and necrosis a premature cell death, being pathological, caused by external factors such as traumas, infections and toxins. The morphological and biochemical characteristics of necrosis and apoptosis are described in Table 2 (Elmore, 2007; Trump et al., 1997; Kewei, 2014).

Microscopes since their invention have played an important role in the exploration of inorganic and organic samples. The investigation of eukaryotic and prokaryotic cells by fluorescence microscopy is only the starting point for the evolution of this area. Far beyond observing damage in the cytoplasmic membrane or the mechanisms of death such as necrosis and apoptosis, one can still through this tool observe structures or even analyze the co-location of some compound or cellular component by the use of fluorophores, immunological techniques and molecular biology.

\section{References}

Abramowitz, M. E. A. Optical Microscopy. National High Magnetic Field Laboratory, The Florida State University 1800. 
Ali, M. N., Sanggwon, A., Soon-Bark, K., Jungho, H. Investigation of live and dead status of airborne bacteria using UVAPS with LIVE/DEAD® BacLight Kit. Journal of Aerosol Science, 2018 v. 115 p. 181-189.

American Public Health Association. Standard Methods for the Examination of Water and Wastewater, 18th edn. 1992, p. 9-39, American Public Health Association, New York.

Bartash, R. and Nori, P. Beta-lactam combination therapy for the treatment of Staphylococcus aureus and Enterococcus species bacteremia: A summary and appraisal of the evidence. International Journal of Infectious Diseases, 2017, v. 63, p. 7-12

Bradbury, S. The Evolution of the Microscope. New York: Pergamon Press, 357 p. 1967.

Dilusha, F., Adhikari, A., Nanayakkara, C. et al., Cytotoxic effects of ergone, a compound isolated from Fulviformes fastuosus. BMC Complementary and Alternative Medicine, 2016 v. 16.

Edinger, A., and Thompson, C. Death by design: apoptosis, necrosis and autophagy. Current Opinion in Cell Biology, 2004, v. 16, p. 663-669.

Elmore, S. Apoptosis: a review of programmed cell death. Toxicol Pathol, 2007, v. 35, p. 495-516.

Fellers, T. J., and Davidson, M. W., Available in:

http://www.olympusconfocal.com/theor y/confocalintro.html $>$.

Feters, G.A., Singh, A., Byun, S., Callis, P.R., Williams, S. Acridine orange staining reaction as an index of physiological activity in E. coli. J. Microbiol. Methods, 1991 v.13 p.87-97.

Fontes, A. Uso de Lasers para Manipulação e Medidas de Células Vivas. 1999. Instituto de Física Gleb Wataghin UNICAMP, Campinas.
Golstein, P., and Kroemer, G. Cell death by necrosis: towards a molecular definition. Trends in Biochemical Sciences, 2007 v. 32, p. 37-43.

Gordon, A. ; Fetersa; Feipeng, P. Y.L., Barry, H. P., Philip, S. S. Physiological assessment of bacteria using fluorochromes. Journal of Microbiological Methods, 1995 v.21 p. 1-13.

Kewei, W. Molecular mechanisms of liver injury: Apoptosis or necrosis. Exp Toxicol Pathol, 2014. V. 66, p. 351-6.

Loehfelm, T. W., Luke, N. R., Campagnari, A. A. Identification and Characterization of an Acinetobacter baumannii Biofilm-Associated Protein. Journal of bacteriology, 2008, p. 10361044

Majeed, A., Nambi, K. S. N., Taju, G., Hameed, A. S. S. 719-733. Cytotoxicity, genotoxicity and oxidative stress of malachite green on the kidney and gill cell lines of freshwater air breathing fish Channa striata. Environmental Science and Pollution Research, 2014 v. 21.

McAuliffe, L., Ellis, R. J., Miles, K., Ayling, R. D., Nicholas, R. A. Biofilm formation by mycoplasma species and its role in environmental persistence and survival. Microbiology, 2006 v.152, p.913.

Mohammadjavad, P., Behnam, K., Yi, L. W. et al., Evaluation of cytotoxic and chemotherapeutic properties of boldine in breast cancer using in vitro and in vivo models. Drug Design, Development and Therapy, 2014, v.8 p.

Ozawa, T. Mechanism of somatic mitochondrial DNA mutations associated with age and diseases. Biochim Biophys Acta, 1995, v. 1271, p. $177-89$.

Paddock, S. W. Confocal Microscopy: Methods and Protocols. 122. 
Schlafer, S., and Meyer, R.L. Confocal microscopy imaging of the biofilm matrix. Journal of Microbiological Methods, 2017 v. 138 p. 50-59.

Smith, S. et al., A Simple Technique for Quantifying Apoptosis in 96-Well Plates. Laboratory Methods in Cell Biology: Biochemistry and Cell Culture, 2012 v. 112, p. 361-368.

Stelzer, M. Restauração de Imagem de Microscopia Confocal Utilizando Técnicas POCS. 2005. (Mestrado em Ciência da Computação). Universidade Federal de São Carlos, São Carlos.
Integrada para Manipulações e Microscopias Confocais. 2007. Instituto de Física Gleb Wataghin, UNICAMP, Campinas.

Trump, B. F., Berezesky, I. K., Chang, S. H., Phelps, P. C. The pathways of cell death: oncosis, apoptosis, and necrosis. Toxicol Pathol, 1997, v. 25, p. 82-8.

Witkowski, A., Ludzik, J., Soyer, P. Telediagnosis with Confocal Microscopy: A Reality or a Dream? Dermatologic Clinics, 2016 v. 34 p. 505-512.

Thoma Z, A. A. Ferramenta Biofotônica

\section{How to cite this article:}

Larissa Souza Amaral and Erich Potrich. 2018. Cell Membrane Damage of Prokaryotes and Analysis of the Cell Death Type in Eukaryotes by Fluorescence Microscopy. Int.J.Curr.Microbiol.App.Sci. 7(02): 795-805. doi: https://doi.org/10.20546/ijcmas.2018.702.101 